\title{
Evidence that leptin genotype is associated with fertility, growth, and milk production in Holstein cows
}

\author{
A. M. Clempson, ${ }^{\star}$ G. E. Pollott, ${ }^{\star}$ J. S. Brickell, ${ }^{\star}$ N. E. Bourne, ${ }^{\star}$ N. Munce, $\neq$ and D. C. Wathes ${ }^{\star 1}$ \\ ${ }^{*}$ Royal Veterinary College, Hawkshead Lane, North Mymms, Hatfield, Hertfordshire, AL9 7TA, UK \\ ¥Merial Animal Health Ltd., Sandringham House, Harlow Business Park, Harlow, Essex, CM19 5TG, UK
}

\begin{abstract}
This study investigated associations between single nucleotide polymorphisms (SNP) in the leptin, leptin receptor, and neuropeptide $\mathrm{Y}(N P Y)$ genes with growth, milk production, and fertility traits. Holstein Friesian heifers from 19 UK dairy farms were recruited at birth, providing an initial population of 509. Animals were monitored until they either reached the end of their second lactation or were culled. Size (weight, height, length, girth) was measured at 1, 6, and 15 mo to assess growth traits. Heifer fertility was assessed by recording age at service, age at conception, age at first calving, and number of services. Cow fertility was assessed by recording days from calving to service and conception, services per conception, percentage of animals in calf at $100 \mathrm{~d}$ after calving and the calving interval in each lactation. Milk production was recorded as days in milk, total milk per lactation, 305-d yield, milk per day, and peak yield. Mixed model analyses revealed that leptin SNP were associated with early skeletal growth (height, A1457G; length, A59V), fertility (UASMS1, UASMS2, A1457G, A59V) and milk production (A59V). The leptin receptor SNP (T945M) was only weakly associated with milk per day and days to first service. The NPY SNP (NPY1) was associated with the prevalence of the animal being in calf $100 \mathrm{~d}$ after calving and 305$\mathrm{d}$ milk yield in the first lactation. The association of leptin SNP with fertility traits in heifers, in addition to lactating cows, suggests that some effects on fertility are direct and not necessarily mediated via altered tissue mobilization. In accord with this, other work has shown that leptin can affect oocyte quality and early embryo development. These results support the use of leptin SNP to inform marker-assisted selection in dairy cows.
\end{abstract}

Key words: polymorphism, growth, productivity, fertility

Received July 15, 2010.

Accepted March 10, 2011.

${ }^{1}$ Corresponding author: dcwathes@rvc.ac.uk

\section{INTRODUCTION}

Leptin is a $16 \mathrm{kDa}$ hormone secreted primarily by white adipose tissue which plays an essential role in the homeostatic regulation of feed intake, energy partitioning, adipose tissue deposition, metabolism, and immune function (Ingvartsen and Boisclair, 2001; Liefers et al., 2005). Many studies have also linked leptin with reproduction. For example, $L e p^{o b} / L e p^{o b}$ mice express a truncated form of the protein and are both obese and infertile, but can have their fertility restored through exogenous leptin treatment (Cunningham et al., 1999). Leptin receptors (LEPR) are present in the ventromedial and arcuate nuclei of the hypothalamus and the anterior pituitary gland, and leptin treatment both in vitro and in vivo can increase gonadotropin secretion as demonstrated in rodents and pigs (Houseknecht et al., 1998). In cattle and sheep, a similar effect on gonadotropins is only observed when animals have been pre-exposed to a severe state of undernutrition (Zieba et al., 2005). Leptin receptors are also present in the ovary where leptin can modulate steroidogenesis (Spicer, 2001) and improve the ability of the oocyte to sustain subsequent embryonic development (Boelhauve et al., 2005).

As leptin concentrations are strongly influenced by adipose tissue mass, leptin is thought to be a key signaling molecule linking nutritional status to reproductive function (Houseknecht et al., 1998; Zieba et al., 2005). An adequate amount of circulating leptin appears necessary for the attainment of puberty (Cunningham et al., 1999), and leptin concentrations in cattle increase in the period preceding puberty (Thorn et al., 2007). Chronic leptin administration to beef heifers failed, however, to induce puberty at an earlier age (Zieba et al., 2005). In dairy cows, leptin concentrations increase throughout pregnancy but start to decrease shortly before calving to reach a nadir in early lactation (Ingvartsen and Boisclair, 2001). Seeber et al. (2002) demonstrated in the rat that pregnant animals enter a leptin-resistant state, associated with a decrease in plasma leptin-binding activity, enabling adiposity and appetite to increase together. The peripartum fall in 
leptin concentrations in cows precedes a major loss of BCS and may, in part, be regulated through decreased plasma insulin concentration (Block et al., 2003). This loss of body condition following parturition occurs because of the mobilization of fat stores to supplement the energy requirements of lactation (Bauman and Currie, 1980; Wathes et al., 2007b). Cows calving with a poor BCS or which have a high precalving BCS but subsequently experience rapid and significant BCS loss, reach a lower nadir in negative energy balance. This is reflected in a delayed onset of estrous cyclicity and a decreased likelihood of conception (Beam and Butler, 1999; Wathes et al., 2007a,b).

Another component of the leptin system is neuropeptide Y (NPY), a 36-AA neurotransmitter involved in the control of appetite, feeding, and energy homeostasis (Bahar and Sweeney, 2008). Concentrations of NPY are elevated when body fat stores are depleted, causing an increase in appetite (Kalra et al., 1991). Therefore, during negative energy balance, NPY levels are expected to be high. Furthermore, NPY has been identified as a primary regulator of leptin activity in the hypothalamus, influencing the release of LH and somatotropin (Kalra et al., 1991), and is, therefore, another suitable candidate to study in relation to fertility.

Previous studies in cattle have associated SNP in leptin, NPY (both located on Bos taurus autosome 4) and LEPR (located on Bos taurus autosome 3) genes with a variety of economically important production traits. Different SNP have been associated with milk yield, milk composition, DMI, and circulating leptin concentrations during late pregnancy in dairy cows and with traits relating to carcass fat composition in beef cattle (van der Lende et al., 2005). Information linking these SNP to growth or fertility traits in dairy cattle is, however, limited. Here, we have investigated associations between polymorphisms in the leptin/NPY system with growth, fertility, and milk production traits in dairy cows in the UK.

\section{MATERIALS AND METHODS}

\section{Animals and Phenotypic Data}

Information on animals, farms and phenotypic measurements has been described previously (Brickell et al., 2009). Briefly, Holstein Friesian heifers $(\mathrm{n}=509)$ born between August 2003 and October 2004 on 18 commercial UK dairy farms and 1 primarily research farm (with 3 groups) were recruited for this study. This provided a total of 21 cohorts of animals (mean cohort size 22, range 15 to 30 animals per cohort). These farms provided a range of management practices representa- tive of those commonly encountered on dairy farms in the UK.

Body weight, height at withers, crown rump length, and heart girth were measured at approximately 1 mo $(28 \pm 0.8 \mathrm{~d}), 6 \mathrm{mo}(184 \pm 0.8 \mathrm{~d}$, pre pubertal $)$, and 15 mo $(452 \pm 2.8 \mathrm{~d}$, postpubertal at the start of the service period) of age. These size measurements were used to assess heifer growth before the start of the breeding period at approximately 15 mo of age.

Fertility was assessed for each animal before first calving and during first and second lactation. For nulliparous heifers, age at first service (based on either the date of first AI or date of first exposure to a bull), and age at first conception were recorded. For those animals in which AI was used exclusively (210/450, 47\% of total served at $15 \mathrm{mo}$ ), the number of services required for conception was recorded. Conception was defined as whether an animal conceived (validated by a positive pregnancy diagnosis or a subsequent calving date) or failed to conceive. The total number of AI services given included heifers that conceived as well as heifers that failed to conceive and were subsequently culled.

Fertility was also measured for each surviving animal throughout the first and second lactation by measuring age at calving, the number of postpartum days for commencement of luteal activity [based on twice weekly milk progesterone measurement (Bulman and Lamming, 1978)], and the number of days after calving to first service. Conception and services required for conception were also recorded in both lactations, as were number of postpartum days to conception, the prevalence of the animal being in calf $100 \mathrm{~d}$ after calving, and the calving interval.

Milk production traits were analyzed for each animal in the first and second lactation by measuring the number of DIM, total milk produced, average milk production per day, 305-d milk yield, and the peak daily milk yield (defined as the highest daily milk volume produced for each animal). These values were obtained from monthly records provided by commercial milk recording services.

Animals were recruited into the study at birth and monitored until the end of their second lactation or until the time of death or culling, if this occurred earlier. The number of records used in each analysis varied depending on the availability of information for the traits and SNP.

\section{Blood Sampling, DNA Extraction, and Genotyping}

Blood samples from each animal were collected from the jugular vein (at $6 \mathrm{mo}$ ) or from the coccygeal vein or artery (at $15 \mathrm{mo}$ ) under the UK Animals (Scientific 
Table 1. Gene name, SNP location, and references of the 7 SNP used in this study

\begin{tabular}{lcllll}
\hline Gene & & $\begin{array}{l}\text { SNP } \\
\text { Name }\end{array}$ & $\begin{array}{l}\text { SNP } \\
\text { identifier }\end{array}$ & $\begin{array}{l}\text { SNP } \\
\text { location }\end{array}$ & Reference \\
\hline Leptin & BTA & UASMS1 & rs 110058647 & Promoter & Nkrumah et al. (2005) \\
& 4 & UASMS2 & rs 109406937 & Promoter & Nkrumah et al. (2005) \\
& & A1457G & ss 319607411 & Promoter & Liefers et al. (2005) \\
& & C963T & rs 109956567 & Promoter & Liefers et al. (2005) \\
& & A252T & rs 29004487 & Exon 2 & Lagonigro et al. (2003) \\
& & E2FB & rs 29004488 & Exon 2 & Buchanan et al. (2002) \\
Leptin receptor & 3 & A59V & rs 29004508 & Exon 3 & Liefers et al. (2003) \\
Neuropeptide Y & 4 & NPY1 & ss 319607410 & Exon 20 & Liefers et al. (2004) \\
& & ss 319607412 & Intron 2 & Sherman et al. (2008) \\
\hline
\end{tabular}

Procedures) Act, 1986. Genotyping of the SNP was carried out by Eurofins Medigenomix GmbH (Martinsried, Germany) using iPLEX biochemistry on a MassARRAY Compact Analyzer (Sequenom, Inc., San Diego, CA) according to manufacturer protocols. The SNP investigated are presented in Table 1 and were as follows: in the leptin gene promoter, UASMS1, UASMS2, A1457G, and C963T; in leptin exon 2, 2 SNP were studied: A252T (which introduces an AA change from Tyr to Phe, also referred to as E2JW) and E2FB (which introduces an AA change from Arg to Cys); in leptin exon 3, an SNP known as A59V (introducing an AA change from Ala to Val) was also studied; and in LEPR, an SNP known as T945M (which introduces an AA change from Tyr to Met) was investigated, as was an SNP in the NPY gene (known as NPY1) of intron 2.

\section{Statistical Analysis}

The genotype frequencies of each polymorphism were examined for deviations from Hardy-Weinberg equilibrium within the population using the $\chi^{2}$ test. The extent of linkage disequilibrium between pairwise genotype combinations was also determined by calculating the correlation coefficient (r) in Haploview software (Barrett et al., 2005).

Preliminary association analyses were carried out using a range of models. For the growth analyses (BW, crown rump length, height at withers, and heart girth), investigations into the type of curve (orthogonal vs. spline) and order of polynomial were conducted. Decisions on the final model were made based on the evaluation of the log-likelihood and size of residual variance for each test. After initial tests, age was fitted within herd-year-season (to account for any differential effects of growth within the farm) and also within SNP. The model used in subsequent analyses was

$$
\begin{aligned}
& Y_{i j k l}=\mu+H Y S B_{i}+\sum_{l}^{z} b_{i z} A g e^{z}+S N P_{j} \\
& +\sum_{l}^{z} b_{j z} A g e^{z}+A_{k}+H_{l}+e_{i j k l},
\end{aligned}
$$

where $Y=$ size/growth measurement; $\mu=$ overall mean; $H Y S B_{i}=$ fixed effect of the $i$ th herd-year-season of birth $(i=1-34) ; \sum_{l}^{z} b_{i z} A g e^{z}=$ regression of the age of the cow in days described by the $i$ th herd-year-season of the regression coefficient $b$, where $z=1$ to $4 ; S N P_{j}=$ the $j$ th genotype of the $\operatorname{SNP}(j=1-3) ; \sum_{l}^{z} b_{j z} A g e^{z}=$ regression of the age of the animal in days described by the $j$ th order of the SNP of the regression coefficient $b$, where $z=1$ to $4 ; A_{k}=k$ th random genetic effect of the animal; $H_{l}=$ the animal permanent environmental effect; and $e_{i j k l}=$ random residual error.

Production traits (DIM, total milk, milk per day, 305-d milk yield, peak daily milk yield) were analyzed with the following mixed model:

$$
Y_{i j k l}=\mu+H Y S C_{i}+A C_{j}+S N P_{k}+A_{l}+e_{i j k l},
$$

where $Y=$ production trait analyzed; $\mu=$ overall mean; $H Y S C_{i}=$ fixed effect of the $i$ th herd-year-season of calving $(i=1-36) ; A C_{j}=j$ th covariate of age at calving; $S N P_{k}=$ fixed effect of the $k$ th genotype of the SNP $(k=1-3) ; A_{l}=l$ th random animal effect; and $e_{i j k l}$ $=$ random residual error.

Fertility traits (age at first service, total number of AI services, conception, services required for conception, age at first conception, age at calving, commencement of luteal activity postpartum, days to first service, days to conception, the prevalence of the animal being in calf $100 \mathrm{~d}$ after calving and the calving interval) were analyzed using a similar approach to model [2]. For fertility traits recorded in the first and second lactation, an additional fixed effect of milk per day was fitted.

The traits analyzed in this study were transformed where necessary to normalize their distribution. Observations on conception and the prevalence of the animal being in calf $100 \mathrm{~d}$ after calving were class variables (1 $=$ yes, $0=$ no) and were, therefore, analyzed using a binary model. The scale for binary traits was related to the linear predictor using a logit link function of the 
form $\mu /(1-\mu)$. Means testing for these traits were carried out on the underlying scale and predicted means were calculated using the inverse link function $1 /[1+$ $\exp (-\mathrm{p})]$, where $\mathrm{p}$ was the linear predictor on the underlying scale.

All analyses were performed using ASREML v2.0 (Gilmour et al., 2006). Fixed effects were only fitted if they made a significant contribution to the overall variance component $(P<0.05)$. All known pedigree information for the preceding 3 generations for each animal were included in all analyses $(\mathrm{n}=2,251)$ to form the additive genetic relationship matrix accounting for the random genetic effect of the cow. Genotype substitution effects for significant associations was calculated using marginal predictions based on the average response of the fixed explanatory variables indicated in models [1] and [2] (Lane and Nelder, 1982; Gilmour et al., 2004; Welham et al., 2004). For model [1], interactions were fitted as single factors to calculate the predictions as described in Gilmour et al. (2006). Predictions were made for each growth trait at 1,6 , and 15 mo of age. Significant differences between the genotype predictions were analyzed using the t-test and standard errors of differences were calculated for each pair of means tested.

A false discovery rate (FDR) was also calculated to account for multiple testing, whereby significance was achieved at an adjusted FDR $q$-value $<0.10$ as described in Mosig et al. (2001).

\section{RESULTS}

\section{Phenotypic Measurements, Genotype Frequencies, and Linkage Disequilibrium}

The phenotypic measurements of the animals are summarized in Table 2. At 15 mo of age, heifers had an average weight and height of $373 \pm 2.4 \mathrm{~kg}$ and 126 $\pm 0.3 \mathrm{~cm}$ respectively (mean $\pm \mathrm{SE}$ ). Of the 509 heifers recruited, 450 survived to first service, which occurred, on average, at $473 \pm 4.5 \mathrm{~d}$. Heifers calved for the first time at $792 \pm 5.3 \mathrm{~d}(\mathrm{n}=395)$ and were, on average, $1,209 \pm 8.4 \mathrm{~d}(\mathrm{n}=329)$ at second calving. Nulliparous heifers required fewer services to conceive than first- or second-lactation cows $(1.43 \pm 0.1,2.29 \pm 0.1$, and 2.28 \pm 0.1 respectively). Fertility tended to be slightly worse in the first than the second lactation, with more days to conception (132 \pm 5 vs. $120 \pm 4 \mathrm{~d})$ and fewer animals were in calf by $100 \mathrm{~d}$ postpartum $(44 \pm 2.5$ vs. $49 \pm$ $3.0 \%$ ), although the commencement of luteal activity was similar ( $28 \pm 1.0$ and $25 \pm 1.4 \mathrm{~d}$, respectively). As expected, all milk production variables increased from the first to the second lactation (milk per day: $26.2 \pm$ 0.3 vs. $29.7 \pm 0.5 \mathrm{~kg} / \mathrm{d}$; 305 -d milk yield: $8,767 \pm 100$ vs. $9,857 \pm 126 \mathrm{~kg}$; and peak daily milk yield: $34.2 \pm$ 0.5 vs. $43.0 \pm 0.6 \mathrm{~kg} / \mathrm{d}$ ).

The genotype frequencies of the SNP investigated are reported in Table 3. Allele frequencies of all SNP were distributed according to the Hardy-Weinberg equilibrium expected values (Barrett et al., 2005). Analysis of the results revealed that UASMS1, C963T, and E2FB and were in close linkage disequilibrium $(\mathrm{r}=0.94$ to 0.98 ) and therefore, only UASMS1 was carried forward for further investigation. Linkage disequilibrium between UASMS2, A1457G, A252T, and A59V was, however, lower ( $\mathrm{r}=0.01$ to 0.59$)$ and hence, these SNP were studied independently. Linkage disequilibrium was also low between the leptin and NPY SNP $(\mathrm{r}=0.01)$ and therefore, these SNP were also studied separately.

\section{Association and Genotypic Substitution Results}

Significant associations between SNP with size, fertility, and milk production traits are summarized in Table 4 , along with the transformations that were used to normalize the data. To determine the influence of different genotypes, the heterozygote animals were used as a reference to calculate the effects that both homozygotes had on the trait. Only the significant associations $(P$ $<0.05$ ) from Table 4 were studied and the significant substitution effects are given in Table 5 . As no significant associations existed between the traits measured with A252T and T945M, these SNP were retired from the study at this stage. For measurements that were transformed, predicted values were reconverted to the original scale to facilitate interpretation.

With respect to growth, the model [1] included the respective size trait at 1,6 , and 15 mo for each animal. For the leptin SNP, A1457G showed a significant association with height at withers. Animals with a homozygote AA genotype were significantly taller than the AG heterozygotes by approximately $1 \mathrm{~cm}$ at both 1 and 15 mo of age. The leptin SNP A59V was associated with crown rump length, whereby animals with the homozygote TT genotype were shorter than the heterozygotes at both 6 mo (by $3.4 \mathrm{~cm}$ ) and $15 \mathrm{mo}$ (by $4.4 \mathrm{~cm}$ ) of age. Trends of association were also observed between UASMS1 and height at withers $(P=0.062)$ and between $\mathrm{A} 59 \mathrm{~V}$ and heart girth $(P=0.083)$. No significant associations were detected between NPY1 and any of the growth traits.

All of the leptin and the NPY SNP studied showed significant associations with some aspect of fertility. Many remained significant after calculation of the FDR despite the fewer number of cows studied in lactation 2 , strengthening the evidence for the associations found. Animals with the homozygote TT genotype for UASMS1 performed consistently better with regards to 
Table 2. Phenotypic measurements for all cows in the study ${ }^{1}$

\begin{tabular}{|c|c|c|c|}
\hline Item & $1 \mathrm{mo}$ & $6 \mathrm{mo}$ & $15 \mathrm{mo}$ \\
\hline \multicolumn{4}{|l|}{ Size } \\
\hline Height at withers, $\mathrm{cm}$ & $80 \pm 0.2(499)$ & $104 \pm 0.3(482)$ & $126 \pm 0.3(430)$ \\
\hline $\mathrm{BW}, \mathrm{kg}$ & $56 \pm 0.7(497)$ & $175 \pm 1.7(463)$ & $373 \pm 2.4(438)$ \\
\hline Crown rump length, $\mathrm{cm}$ & $94 \pm 0.4(500)$ & $135 \pm 0.5(482)$ & $169 \pm 0.5(431)$ \\
\hline Heart girth, cm & $89 \pm 0.4(500)$ & $131 \pm 0.4(482)$ & $174 \pm 0.5(430)$ \\
\hline Fertility & Nulliparous & Lactation 1 & Lactation 2 \\
\hline Age at first service, $\mathrm{d}$ & $473 \pm 4.5(369)$ & & \\
\hline Age at first conception, $\mathrm{d}$ & $511 \pm 5.3(408)$ & & \\
\hline Total no. of AI services & $1.5 \pm 0.1(217)$ & & \\
\hline Age at calving, $\mathrm{d}$ & & $792 \pm 5.3(395)$ & $1,209 \pm 8.4(329)$ \\
\hline Commencement of luteal activity, $\mathrm{d}$ & & $28 \pm 1.0(204)$ & $25 \pm 1.4(85)$ \\
\hline Days to first service, $\mathrm{d}$ & & $81.6 \pm 1.6(387)$ & $74.4 \pm 1.7(276)$ \\
\hline Services, $\mathrm{n}$ & $1.43 \pm 0.1(210)$ & $2.29 \pm 0.1(355)$ & $2.28 \pm 0.1(260)$ \\
\hline Conception, \% & $96 \pm 1.0(450)$ & $93 \pm 1.3(386)$ & $95 \pm 1.4(258)$ \\
\hline Days to conception, $\mathrm{d}$ & & $132 \pm 5(374)$ & $120 \pm 4(272)$ \\
\hline In calf $100 \mathrm{~d}$ postpartum, $\%$ & & $44 \pm 2.5(389)$ & $49 \pm 3.0(272)$ \\
\hline Calving interval, d & & $409 \pm 5(329)$ & $391 \pm 5(214)$ \\
\hline \multicolumn{4}{|l|}{ Milk production } \\
\hline DIM, d & & $345 \pm 7(387)$ & $321 \pm 6(273)$ \\
\hline Total milk, $\mathrm{kg}$ & & $9,220 \pm 192(387)$ & $9,800 \pm 190(267)$ \\
\hline Milk per day, $\mathrm{kg} / \mathrm{d}$ & & $26.2 \pm 0.3(366)$ & $29.7 \pm 0.5(198)$ \\
\hline 305-d milk yield, kg & & $8,767 \pm 100(248)$ & $9,857 \pm 126(174)$ \\
\hline Peak milk yield, $\mathrm{kg} / \mathrm{d}$ & & $34.2 \pm 0.5(206)$ & $43.0 \pm 0.6(170)$ \\
\hline
\end{tabular}

${ }^{1}$ Values are presented as mean \pm SEM with the number of values included in each calculation in parentheses.

fertility than the CT heterozygotes, with a $7 \%$ increase in the prevalence of the animal being in calf $100 \mathrm{~d}$ after calving in the first lactation and a decrease in days to conception by $23 \mathrm{~d}$ in the second lactation, leading to a 22 -d shorter calving interval. The leptin SNP A1457G was significantly associated with the total number of AI services in nulliparous heifers, whereby the GG animals required 0.13 fewer services than AG animals. Significant associations were also found between this SNP and days to conception and calving interval in the second lactation, whereby animals with the AA genotype conceived approximately 1 mo earlier $(29 \mathrm{~d})$ than the AG heterozygotes, resulting in a significantly shorter calving interval period (by $30 \mathrm{~d}$ ). The leptin SNP UASMS2 had the greatest influence on heifer fertility. Here, TT homozygotes required significantly more services for conception (an increase of 1.1) and also received a greater total number of services (an increase of 1.3) than the CT heterozygotes. A trend also existed for the UASMS2 genotype to influence commencement of luteal activity in the first lactation $(P=0.077)$. Heifers with a homozygous CC genotype of A59V were significantly younger at first service and subsequently had an earlier age at first calving (by $16 \mathrm{~d}$ and $15 \mathrm{~d}$ respectively). The leptin SNP NPY1 was significantly associated with the likelihood of conceiving within 100 $\mathrm{d}$ after calving in the first lactation: animals with the GG genotype were $8 \%$ more likely to conceive within $100 \mathrm{~d}$ postpartum than heterozygotes.
In contrast to the many associations found with fertility, the only leptin SNP significantly associated with the milk production traits was A59V, which had significant associations with both milk per day (lactation 1) and 305-d milk yield (lactation 2). Compared with the heterozygote, the TT substitution of A59V significantly decreased milk output by $3.3 \mathrm{~kg} / \mathrm{d}$ in lactation 1 and cows with this genotype also had a decreased 305-d milk yield by, on average, $1,365 \mathrm{~kg}$ in lactation 2 . The SNP NPY1 was also significantly associated with 305d milk yield in lactation 1 , whereby animals with the

Table 3. SNP genotype frequencies across the population of cows studied

\begin{tabular}{lccc}
\hline & \multicolumn{3}{c}{ Genotype } \\
\cline { 2 - 4 } SNP & CC & CT & TT \\
\hline UASMS1 & 0.18 & 0.45 & 0.37 \\
UASMS2 & 0.74 & 0.24 & 0.02 \\
C963T & 0.37 & 0.47 & 0.16 \\
E2FB & 0.35 & 0.48 & 0.17 \\
A59V & 0.61 & 0.33 & 0.06 \\
T945M & 0.85 & 0.15 & 0.00 \\
& GG & AG & AA \\
\cline { 2 - 4 } A1457G & 0.30 & 0.47 & 0.23 \\
NPY1 & 0.70 & 0.27 & 0.03 \\
& AA & AT & TT \\
\cline { 2 - 4 } A252T & 0.95 & 0.05 & 0.00 \\
\hline
\end{tabular}


Table 4. Probabilities of associations between SNP with juvenile size, fertility, and milk production traits ${ }^{1}$

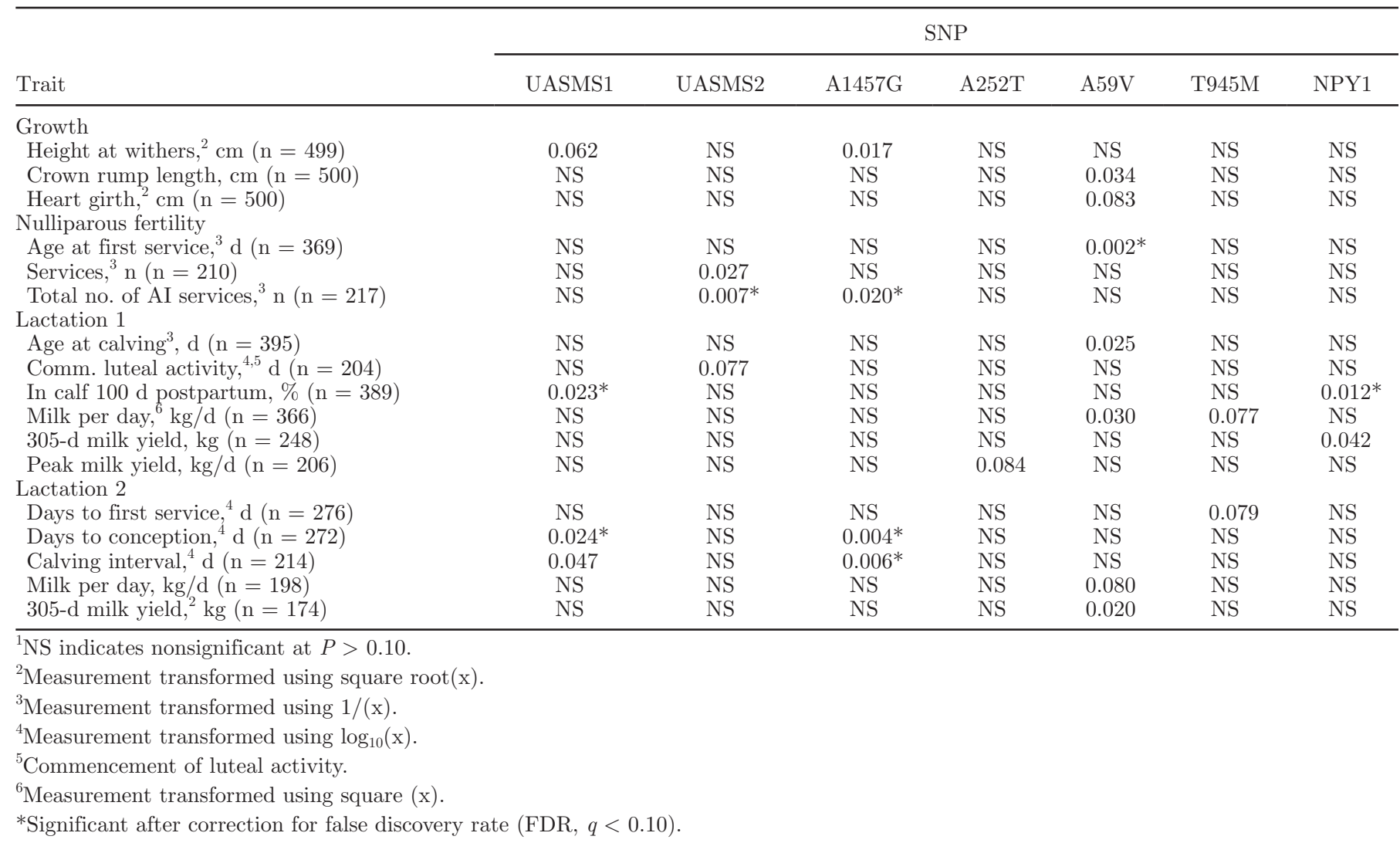

AA genotype had a significantly lower 305-d milk yield than the heterozygotes by $1,304 \mathrm{~kg}$.

\section{DISCUSSION}

The results of this study have revealed several strong associations between leptin SNP and fertility traits. Some of these were present in nulliparous heifers, whereas those found in lactating cows were significant even though milk production was accounted for in the model. In summary, animals with the TT genotype for $\mathrm{A} 59 \mathrm{~V}$ had a decreased crown rump length in the period around puberty (6-15 mo), were served and calved for the first time approximately 2 wk earlier and produced less milk in both lactations. However, they only represented $6 \%$ of the population. Cows with the AA genotype for A1457G were taller as heifers and had considerably better fertility in their second lactation, reflected in an approximate 1-mo decrease in both days to conception and calving interval. Animals with the TT genotype for UASMS 2 were rare $(2 \%$ of population) and had worse fertility as heifers. Only 11 of these animals calved, perhaps explaining the lack of associations in older animals. In contrast, animals with the TT genotype for UASMS1 had better fertility as lactat- ing cows. For NPY1, the AA genotype was also rare in the population (only 3\%): these animals produced considerably less milk in their first lactation, whereas those with the GG genotype had a better likelihood of conceiving within $100 \mathrm{~d}$ of calving.

Numerous SNP have been identified in leptin, including UASMS1, UASMS2, A1457G, and C963T, which are all located in the promoter and may, therefore, alter leptin gene expression (van der Lende et al., 2005). Several functional transcription factor binding domains have been identified in the leptin promoter, including the CAAT/enhancer binding domain, SP1, LP1, ADD1/ SREBP1, HIF-1, and peroxisome proliferator-activated receptor $\gamma$ (PPAR $\gamma$; van der Lende et al., 2005). The leptin SNP E2FB and A252T are located in exon 2 and both introduce AA changes (Arg to Cys at position 305 and Tyr to Phe at position 252, respectively), which may alter the tertiary structure of the mature protein (Buchanan et al., 2002; Lagonigro et al., 2003; Liefers et al., 2003). The leptin SNP A59V is located in exon 3 and also introduces an AA change from Ala to Val at position 59 (Liefers et al., 2003).

In accordance with Banos et al. (2008), we found large linkage disequilibrium values between UASMS1, C963T, and E2FB. Only results for UASMS1 have, 
Table 5. Genotype substitution effects between heterozygotes and homozygotes for significant associations between leptin and neuropeptide Y SNP with growth, fertility, and milk production traits ${ }^{1}$

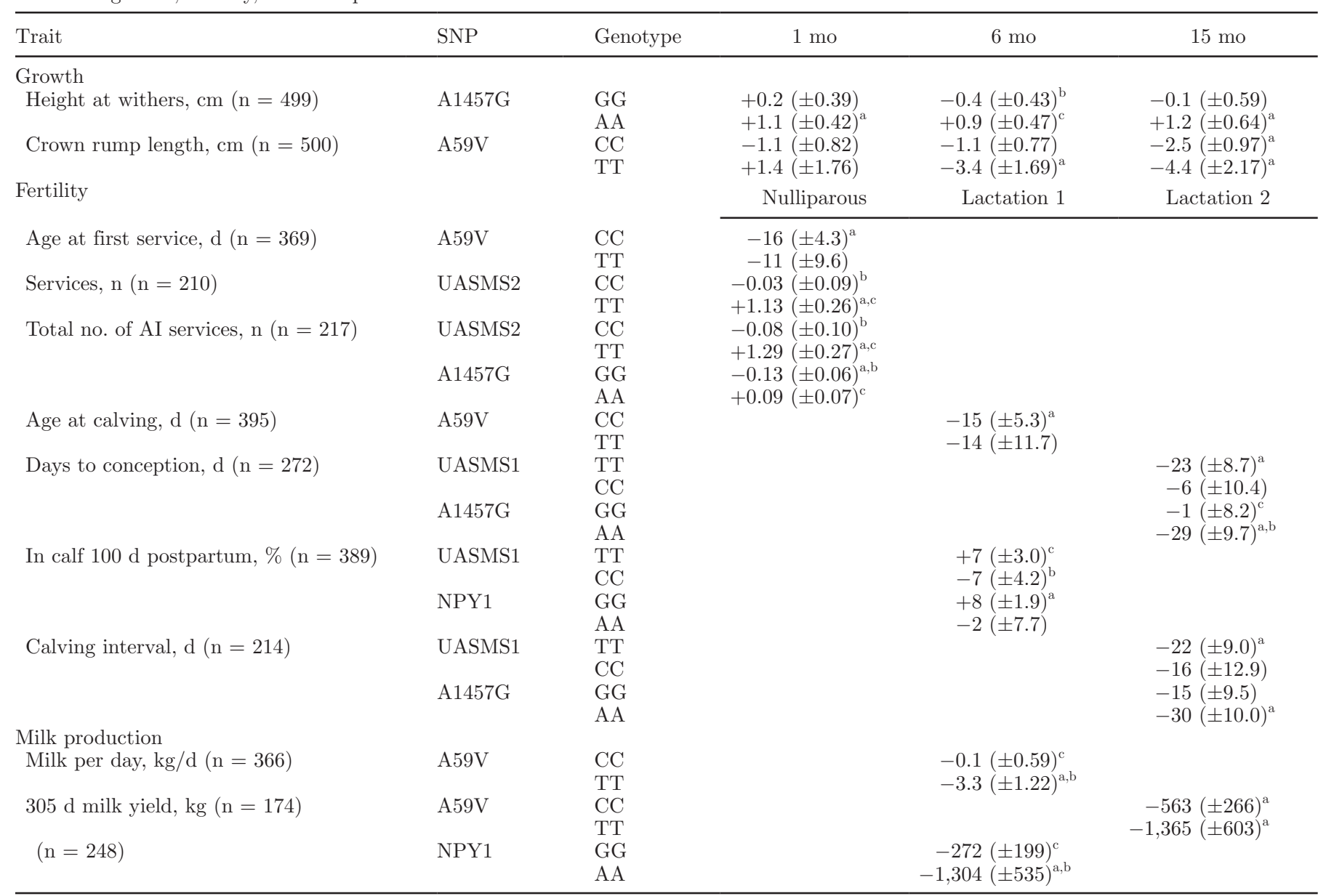

${ }^{a}$ Homozygote significantly different from the heterozygote $(P<0.05)$.

${ }^{\mathrm{b}, \mathrm{c}}$ Significant differences between the 2 homozygotes $(\mathrm{b}<\mathrm{c} ; P<0.05)$.

${ }^{1}$ Values presented as mean $( \pm \mathrm{SE}$ of the differences of means).

therefore, been reported and it is not possible to determine which of these SNP (if any) were having the causative effects. Also in accord with Banos et al. (2008), the genotype frequency of A252T was highly skewed, with the TT genotype being unrepresented in this study. It also remains uncertain as to whether the associations of leptin SNP with the growth and fertility traits reported here were mediated via changes in circulating concentrations of the hormone, as these were not measured in the present study. Liefers et al. (2003) reported that cows carrying the TT genotype of A59V had significantly higher leptin concentrations during late pregnancy but not postpartum.

We are unaware of previous studies that have investigated leptin SNP in association with growth traits in dairy heifers, although DeVuyst et al. (2008) reported that crossbred calves carrying the $\mathrm{T}$ allele for $\mathrm{E} 2 \mathrm{FB}$ were heavier at weaning. Furthermore, polymorphisms in LEPR were associated with growth traits in Nanyang cattle, where they had significant effects on height, length, heart girth, weight, and ADG at 6 and 12 mo of age (Guo et al., 2008). In growing cattle, circulating leptin concentrations rise before the onset of puberty (Zieba et al., 2005). In our study, A1457G was significantly associated with juvenile height and a trend with height was observed with UASMS1. Furthermore, A $59 \mathrm{~V}$ was significantly associated with crown rump length and a trend of association was observed with heart girth. Leptin may influence growth via effects on body composition and feed intake (Lagonigro et al., 2003). We have previously reported that both height at birth and weight at calving are heritable characteristics in dairy heifers (Swali and Wathes, 2006). In human studies, height has been estimated to be 80 to $90 \%$ heritable (Sovio et al., 2009) and is regarded as a classic polygenic trait that has been the focus of several 
genome-wide association studies. So far, over 40 loci have been associated with human stature (Weedon and Frayling, 2008) and, among these, leptin is one of a complex network of endocrine signals that contributes to longitudinal bone growth through actions on chondrocytes and osteoblasts (Nilsson et al., 2005). In juvenile animals, leptin is thought to stimulate bone growth, whereas it may decrease bone remodeling in the mature skeleton and, hence, influence bone mass (Thomas, 2004).

Leptin SNP have previously been associated with milk yield, milk composition, and DMI in dairy cows (van der Lende et al., 2005). In our population of British Holstein-Friesian cows significant associations existed between A59V with both milk per day and 305-d milk yield. The leptin SNP UASMS1, UASMS2, A1457G, and A252T were not significantly associated with milk production in this study, although Banos et al. (2008) did previously report an association between A1457G and milk yield in British cows $(P<0.03)$, with a trend of association between this trait and UASMS1 $(P<0.09)$.

Most of the SNP investigated here showed some significant associations with important fertility traits including age at first service (A59V), services for conception (UASMS2) and total services (A1457G and UASMS2), days to conception (UASMS1 and A1457G), proportion of animals in calf at $100 \mathrm{~d}$ postpartum (UASMS1 and NPY1), and calving interval (UASMS1 and A1457G). Although an indirect effect of leptin on fertility is possible via alterations in tissue mobilization, the results also support a role for a direct action of leptin on the reproductive system. Almeida et al. (2003) found a significant association between another leptin SNP, RFLP1, and both weight at first calving and subsequent calving interval in beef heifers. In contrast to our results, Oikonomou et al. (2009) investigated the relationship between leptin SNP and several fertility traits in a herd of Greek dairy cows and only detected a marginal increase in the frequency of metritis with an SNP located in intron 2. This study was based exclusively on primiparous animals, whereas the effects shown in the present paper were most pronounced in nulliparous and second-lactation cows. We have previously shown that circulating leptin levels were higher in primiparous heifers than in older animals both before calving and in early lactation (Wathes et al., 2007b), so it is possible that this age difference may influence the outcome.

The postpartum period is a time when most cows are in energy deficit, and the low leptin levels at this time may be associated with reduced gonadotropin secretion, thus prolonging the interval to first ovulation (Liefers et al., 2005). In support of this, leptin and commence- ment of luteal activity were significantly associated in multiparous but not primiparous cows (Wathes et al., 2007a). The work of Zieba et al. (2005) has shown that, in ruminants, a state of severe undernutrition sensitizes the hypothalamus and pituitary to the effects of leptin, possibly via alterations in LEPR concentrations. In the present study, only one weak association $(P<0.077)$ between UASMS2 and commencement of luteal activity was observed. Together these results indicate that an effect of leptin SNP on fertility via an action on gonadotropin secretion is possible, but perhaps not of major importance.

In contrast, a growing body of evidence suggests that leptin is an important regulator of fertility at the ovarian level. Leptin receptors in ruminants are present in both the follicle and corpus luteum (Spicer, 2001; Muñoz-Gutiérrez et al., 2005; Nicklin et al., 2007). In cultured granulosa cells, leptin alone has little effect, but high leptin concentrations can inhibit insulin or IGF-I-stimulated estradiol production (Spicer, 2001). Infusion of leptin to cyclic ewes also decreased circulating estradiol concentrations (Muñoz-Gutiérrez et al., 2005). In contrast, leptin alone did not alter bovine luteal cell progesterone production, but had a stimulatory effect when combined with IGF-I (Nicklin et al., 2007). In addition, a series of papers in mice (Ye et al., 2009), pigs (Craig et al., 2004), and cattle (Boelhauve et al., 2005) have consistently reported effects of leptin on improving oocyte maturation, increasing fertilization rate in vitro and increasing the proportion of embryos developing to the blastocyst stage. If the leptin SNP studied can modulate the activity of leptin on the developing follicle and oocyte, this could clearly influence conception rates in both nulliparous heifers and older cows as we report here.

The LEPR SNP T945M was only weakly associated with milk per day (lactation 1) and days to first service (lactation 2), suggesting that this SNP plays only a small role in influencing milk production and fertility. This is in accord with the findings of Banos et al. (2008) who also found no significant associations with milk production, feed intake, or body energy traits in UK dairy cows. Despite this, the LEPR plays a critical role in the activation of several downstream signaling pathways including the janus kinases/signal transducer and activation of transcription (JAK/STAT) pathway (Cirillo et al., 2008) to influence NPY expression, cell proliferation, and cell survival (Higuchi et al., 2005). Single nucleotide polymorphisms of the STAT genes have previously been associated with milk production traits in Holstein cows (Cobanoglu et al., 2006) and carcass traits in feedlot cattle (Rincon et al., 2009). Other studies have shown that the JAK/STAT pathway is active during early embryonic development 
(Truchet et al., 2004). Khatib et al., (2008, 2009) used an in vitro fertilization system to demonstrate that STAT1, STAT3, and STAT5A polymorphisms were all associated with fertilization rate and early embryonic survival in dairy cattle. Recently, we also reported significant associations between leptin SNP and perinatal mortality in Holstein-Friesian heifers at first calving (Brickell et al., 2010). Together, these results indicate that proper functioning of the leptin-NPY system is essential for fertilization and subsequent survival of the embryo and neonate in dairy cows.

Finally, the NPY SNP NPY1 was significantly associated with milk production, whereby the rare AA genotype had a significantly lower 305-d milk yield in lactation 1, whereas animals with the GG genotype were more likely to be in calf by $100 \mathrm{~d}$ postpartum than the heterozygous animals. Neuropeptide Y is an important regulator of appetite, which may subsequently influence postpartum negative energy balance (Bahar and Sweeney, 2008). This supports the association found with the proportion of animal in calf by $100 \mathrm{~d}$, as the GG animals may have had an improved energy balance profile after calving. Three SNP in NPY have also previously been associated with marbling, average daily gain, BW, and feed conversion ratio in beef cattle (Sherman et al., 2008), although in the dairy heifers studied here, this gene was not associated with heifer growth traits.

\section{Genetic Effects of SNP}

The results presented here provide some interesting insights into the genetics of leptin and NPY SNP. Taking A1457G as an example, the results in Table 5 suggest that polymorphisms of this marker were associated with differences in 4 traits, although several are related. Considering calving interval and days to conception, then the A allele appears to be recessive and as a homozygote is associated with an approximate 29-d decrease in both traits. However, for total number of AI services, A appears to be the dominant allele as AA is associated with 0.09 more services per animal. This SNP is also linked to changes in withers height at 1 and 6 mo. In this case, $\mathrm{G}$ appears to be partially dominant at $1 \mathrm{mo}$ of age and the heterozygote is intermediate at $6 \mathrm{mo}$; in both cases the AA genotype is associated with taller animals. Given the similar allele frequencies of the 2 polymorphisms, scope for selection exists to improve fertility by increasing the frequency of the AA genotype in Holstein populations.

A dramatic change in performance was also seen in animals carrying the AA genotype of the NPY1 of
NPY; these animals produced $1,304 \mathrm{~kg}$ less milk than the AG heterozygote and 1,032 kg less than the GG homozygote. This implies that the $\mathrm{G}$ allele was dominant and had a large effect by increasing milk production in the first lactation. With the increased selection for high milk yield practiced in the Holstein breed, it is not surprising that the AA genotype only had an incidence of 0.03 in our population and an allele frequency of 0.165 for A. However, due to the dominance of the $\mathrm{G}$ allele, it is unlikely that the A allele will be completely eliminated from the population, except by targeted selection against this allele.

Polymorphisms in the A59V marker produced different performance in 5 traits. In 4 of the traits, the heterozygote had a higher level of performance than either of the 2 homozygotes. Compared with the heterozygote, the rarer homozygote (TT; genotype frequency 0.06 ) had a lower second lactation 305-d milk yield, a lower average daily milk yield in lactation 1, and had a shorter crown rump length at both 6 and 15 mo of age. The CC genotype also had lower 305-d milk yield, was younger at first calving and first service and had a smaller crown to rump length than the heterozygote. A genetic model such as seen in this SNP presents a problem to animal breeders. Clearly the heterozygote is the preferred genotype, but it is not possible to maintain a viable heterozygote population without using the 2 homozygotes, both of which cause a decrease in performance in several traits. Although our results are supportive of overdominance effects for crown rump length at 15 mo and 305-d milk yield, this effect is perceived as a rarity in whole animal studies. Furthermore, this investigation was only based on a relatively small number of animals, and, therefore, the A59V SNP should be analyzed in a larger population to confirm whether overdominance in present. Despite this, an increasing body of evidence from research at the SNP level suggests that this phenomenon is more common than first thought (Takeshima et al., 2008; Clempson et al., 2010), suggesting that overdominance for this SNP is possible.

Both days to conception and calving interval were affected by polymorphisms in the UASMS1 SNP, the TT genotype being associated with a decrease of about $22 \mathrm{~d}$ in both traits. This effect was similar to that of the AA genotype of the A1457G SNP. The linkage disequilibrium between these 2 SNP was 0.59 , and both were found in the promoter region of the leptin gene.

Fertility in the form of service efficiency was affected by genotypic differences in the UASMS2 SNP; the TT genotype appearing to be associated with more services per conception. In this case, the $\mathrm{C}$ allele was dominant 
over $\mathrm{T}$ and the low frequency of the TT genotype indicates that elimination of the deleterious allele could be possible.

We have shown some large differences in production between polymorphisms of a few SNP in the leptin and NPY regions of the Holstein genome. Selection directly for specific genotypes could significantly change performance in a few generations, particularly in fertility traits. Exclusive use of the AA genotype of the A1457G SNP or the TT genotype of UASMS1 could decrease days to conception and calving intervals by $>20 \mathrm{~d}$. These are not rare genotypes in our population and, if similar frequencies were found in the general Holstein population, progress could be made relatively quickly toward improving fertility. However, more research is needed to determine whether these SNP have a causative effect themselves or are in linkage disequilibrium with neighboring causative SNP. Analyzing the results on a greater number of animals would also confirm the associations and patterns linkage disequilibrium reported here.

\section{CONCLUSIONS}

This study has highlighted significant associations between leptin and NPY SNP with important growth, fertility, and milk production traits. We believe that we are the first to report many of the associations between leptin SNP and fertility traits. Some of these may be independent of milk yield, as available evidence suggests that leptin can influence fertility at the ovarian level. This study provides further evidence that SNP in the leptin system may be useful in marker-assisted selection to improve the performance of the dairy cow and highlights the need of selection policies to consider the effects of growth and fertility rather than milk production exclusively.

\section{ACKNOWLEDGMENTS}

We are grateful to Department for Environment, Food and Rural Affairs (Defra, London, UK) and DairyCo (Kenilworth, Warwickshire, UK) for funding the collection of the phenotypic data used in this study and to all the farmers and veterinary surgeons that assisted in the project. A. M. Clempson was supported by a Biotechnology and Biological Sciences Research Council (BBSRC) Council for Advancement and Support of Education (CASE) award. We also thank Merial Animal Health Ltd. (Harlow, Essex, UK) for acting as CASE partners and undertaking the genotype analysis.

\section{REFERENCES}

Almeida, S. E. M., E. A. Almeida, J. C. F. Moraes, and T. A. Weimer. 2003. Molecular markers in the $L E P$ gene and reproductive performance of beef cattle. J. Anim. Breed. Genet. 120:106-113.
Bahar, B., and T. Sweeney. 2008. Mapping of the transcription start site (TSS) and identification of SNP in the bovine neuropeptide Y (NPY) gene. BMC Genet. 9:91.

Banos, G., J. A. Woolliams, B. W. Woodward, A. B. Forbes, and M. P. Coffey. 2008. Impact of single nucleotide polymorphisms in leptin, leptin receptor, growth hormone receptor and diacylglycerol acyltransferase (DGAT1) gene loci on milk production, feed, and body energy traits of UK dairy cows. J. Dairy Sci. 91:3190-3200.

Barrett, J. C., B. Fry, J. Maller, and M. J. Daly. 2005. Haploview: Analysis and visualization of LD and haplotype maps. Bioinformatics 21:263-265.

Bauman, D. E., and W. B. Currie. 1980. Partitioning of nutrients during pregnancy and lactation: A review of mechanisms involving homeostasis and homeorhesis. J. Dairy Sci. 63:1514-1529.

Beam, S. W., and W. R. Butler. 1999. Effects of energy balance on follicular development and first ovulation in postpartum dairy cows. J. Reprod. Fertil. Suppl. 54:411-424.

Block, S. S., R. P. Rhoads, D. E. Bauman, R. A. Ehrhardt, M. A. McGuire, B. A. Crooker, J. M. Griinari, T. R. Mackle, W. J. Weber, M. E. Van Amburgh, and Y. R. Boisclair. 2003. Demonstration of a role for insulin in the regulation of leptin in lactating dairy cows. J. Dairy Sci. 86:3508-3515.

Boelhauve, M., F. Sinowatz, E. Wolf, and F. F. Paula-Lopes. 2005. Maturation of bovine oocytes in the presence of leptin improves development and reduces apoptosis of in vitro-produced blastocysts. Biol. Reprod. 73:737-744.

Brickell, J. S., N. Bourne, M. M. McGowan, and D. C. Wathes. 2009. Effect of growth and development during the rearing period on the subsequent fertility of nulliparous Holstein-Friesian heifers. Theriogenology 72:408-416.

Brickell, J. S., G. E. Pollott, A. M. Clempson, N. Otter, and D. C. Wathes. 2010. Polymorphisms in the bovine leptin gene associated with perinatal mortality in Holstein-Friesian heifers. J. Dairy Sci. 93:340-347.

Buchanan, F. C., C. J. Fitzsimmons, A. G. Van Kessel, T. D. Thue, D. C. Winkelman-Sim, and S. M. Schmutz. 2002. Association of a missense mutation in the bovine leptin gene with carcass fat content and leptin mRNA levels. Genet. Sel. Evol. 34:105-116.

Bulman, D. C., and G. E. Lamming. 1978. Milk progesterone levels in relation to conception, repeat breeding and factors influencing acyclicity in dairy cows. J. Reprod. Fertil. 54:447-458.

Cirillo, D., A. M. Rachiglio, R. Montagna, A. Giordano, and N. Normanno. 2008. Leptin signaling in breast cancer: An overview. J. Cell. Biochem. 105:956-964.

Clempson, A. M., G. E. Pollott, J. S. Brickell, N. Munce, and D. C. Wathes. 2010. Associations between single nucleotide polymorphisms in the Lep and TFAM genes with growth and fertility in UK Holstein-Friesian dairy cows. CD-Rom Commun. 246 in Proc. 9th World Congr. Genet. Appl. Livest. Prod.

Cobanoglu, O., I. Zaitoun, Y. M. Chang, G. E. Shook, and H. Khatib. 2006. Effects of the signal transducer and activator of transcription 1 (STAT1) gene on milk production traits in Holstein dairy cattle. J. Dairy Sci. 89:4433-4437.

Craig, J., H. Zhu, P. W. Dyce, J. Petrik, and J. Li. 2004. Leptin enhances oocyte nuclear and cytoplasmic maturation via the mitogen-activated protein kinase pathway. Endocrinology 145:53555363.

Cunningham, M. J., D. K. Clifton, and R. A. Steiner. 1999. Leptin's actions on the reproductive axis: Perspectives and mechanisms. Biol. Reprod. 60:216-222.

DeVuyst, E. A., M. L. Bauer, F. C. Cheng, J. Mitchell, and D. Larson. 2008. The impact of a leptin gene SNP on beef calf weaning weights. Anim. Genet. 39:284-286.

Gilmour, A. R., B. R. Cullis, S. Welham, B. J. Gogel, and R. Thompson. 2004. An efficient computing strategy for prediction in mixed linear models. Comput. Stat. Data Anal. 44:571-586.

Gilmour, A. R., B. J. Gogel, B. R. Cullis, and R. Thompson. 2006 ASREML User Guide. Release 2.0. VSN International Ltd., Hemel Hempstead, UK. 
Guo, Y., H. Chen, X. Lan, B. Zhang, C. Pan, L. Zhang, C. Zhang, and M. Zhao. 2008. Novel SNPs of the bovine LEPR gene and their association with growth traits. Biochem. Genet. 46:828-834.

Higuchi, H., A. Hasegawa, and T. Yamaguchi. 2005. Transcriptional regulation of neuronal genes and its effect on neural functions: Transcriptional regulation of neuropeptide $\mathrm{Y}$ gene by leptin and its effect on feeding. J. Pharmacol. Sci. 98:225-231.

Houseknecht, K. L., C. A. Baile, R. L. Matteri, and M. E. Spurlock. 1998. The biology of leptin: A review. J. Anim. Sci. 76:1405-1420.

Ingvartsen, K. L., and Y. R. Boisclair. 2001. Leptin and the regulation of food intake, energy homeostasis and immunity with special focus on periparturient ruminants. Domest. Anim. Endocrinol. $21: 215-250$.

Kalra, S. P., M. G. Dube, A. Sahu, C. P. Phelps, and P. S. Kalra. 1991. Neuropeptide Y secretion increases in the paraventricular nucleus in association with increased appetite for food. Proc. Natl. Acad. Sci. USA 88:10931-10935

Khatib, H., W. Huang, D. Mikheil, V. Schutzkus, and R. L. Monson. 2009. Effects of signal transducer and activator of transcription (STAT) genes STAT1 and STAT3 genotypic combinations on fertilization and embryonic survival rates in Holstein cattle. J. Dairy Sci. 92:6186-6191.

Khatib, H., R. L. Monson, V. Schutzkus, D. M. Kohl, G. J. M. Rosa, and J. J. Rutledge. 2008. Mutations in the STAT5A gene are associated with embryonic survival and milk composition in cattle. J. Dairy Sci. 91:784-793.

Lagonigro, R., P. Wiener, F. Pilla, J. A. Woolliams, and J. L. Williams. 2003. A new mutation in the coding region of the bovine leptin gene associated with feed intake. Anim. Genet. 34:371-374.

Lane, P. W., and J. A. Nelder. 1982. Analysis of covariance and standardization as instances of prediction. Biometrics 38:613-621.

Liefers, S. C., M. F. te Pas, R. F. Veerkamp, Y. Chilliard, C. Delavaud, R. Gerritsen, and T. van der Lende. 2003. Association of leptin gene polymorphisms with serum leptin concentration in dairy cows. Mamm. Genome 14:657-663.

Liefers, S. C., R. F. Veerkamp, M. F. te Pas, Y. Chilliard, and T. van der Lende. 2005. Genetics and physiology of leptin in periparturient dairy cows. Domest. Anim. Endocrinol. 29:227-238.

Liefers, S. C., R. F. Veerkamp, M. F. te Pas, C. Delavaud, Y. Chilliard, and T. van der Lende. 2004. A missense mutation in the bovine leptin receptor gene is associated with leptin concentrations during late pregnancy. Anim. Genet. 35:138-141.

Mosig, M. O., E. Lipkin, G. Khutoreskaya, E. Tchourzyna, M. Soller, and A. Friedmann. 2001. A whole genome scan for quantitative trait loci affecting milk protein percentage in Israeli-Holstein cattle, by means of selective milk DNA pooling in a daughter design, using an adjusted false discovery rate criterion. Genetics 157:1683-1698.

Muñoz-Gutiérrez, M., P. A. Findlay, C. L. Adam, G. Wax, B. K. Campbell, N. R. Kendall, M. Khalid, M. Forsberg, and R. J. Scaramuzzi. 2005. The ovarian expression of mRNAs for aromatase, IGF-I receptor, IGF-binding protein-2, -4 and -5 , leptin and leptin receptor in cycling ewes after three days of leptin infusion. Reproduction 130:869-881.

Nicklin, L. T., R. S. Robinson, P. Marsters, B. K. Campbell, G. E. Mann, and M. G. Hunter. 2007. Leptin in the bovine corpus luteum: Receptor expression and effects on progesterone production. Mol. Reprod. Dev. 74:724-729.

Nilsson, O., R. Marino, F. de Luca, M. Phillip, and J. Baron. 2005. Endocrine regulation of the growth plate. Horm. Res. 64:157-165.

Nkrumah, J. D., C. Li, J. Yu, C. Hansen, D. H. Keisler, and S. S. Moore. 2005. Polymorphisms in the bovine leptin promoter associated with serum leptin concentration, growth, feed intake, feeding behavior, and measures of carcass merit. J. Anim. Sci. 83:20-28.

Oikonomou, G., F. Angelopoulou, G. Arsenos, D. Zygoyiannis, and G. Banos. 2009. The effects of polymorphisms in the DGAT, leptin and growth hormone receptor gene loci on body energy, blood metabolic and reproductive traits of Holstein cows. Anim. Genet. $40: 10-17$
Rincon, G., E. A. Farber, C. R. Farber, J. D. Nkrumah, and J. F. Medrano. 2009. Polymorphisms in the STAT6 gene and their association with carcass traits in feedlot cattle. Anim. Genet. 40:878-882.

Seeber, R. M., J. T. Smith, and B. J. Waddell. 2002. Plasma leptinbinding activity and hypothalamic leptin receptor expression during pregnancy and lactation in the rat. Biol. Reprod. 66:17621767.

Sherman, E. L., J. D. Nkrumah, B. M. Murdoch, C. Li, Z. Wang, A. $\mathrm{Fu}$, and S. S. Moore. 2008. Polymorphisms and haplotypes in the bovine neuropeptide $\mathrm{Y}$, growth hormone receptor, ghrelin, insulinlike growth factor 2 , and uncoupling proteins 2 and 3 genes and their associations with measures of growth, performance, feed efficiency, and carcass merit in beef cattle. J. Anim. Sci. 86:1-16.

Sovio, U., A. J. Bennett, I. Y. Millwood, J. Molitor, P. F. O'Reilly, N. J. Timpson, M. Kaakinen, J. Laitinen, J. Haukka, D. Pillas, I. Tzoulaki, J. Molitor, C. Hoggart, L. J. M. Coin, J. Whittaker, A. Pouta, A.-L. Hartikainen, N. B. Freimer, E. Widen, L. Peltonen, P. Elliott, M. I. McCarthy, and M.-R. Jarvelin. 2009. Genetic determinants of height growth assessed longitudinally from infancy to adulthood in the northern Finland birth cohort 1966. PLoS Genet. 5:e1000409.

Spicer, L. J. 2001. Leptin: A possible metabolic signal affecting reproduction. Domest. Anim. Endocrinol. 21:251-270.

Swali, A., and D. C. Wathes. 2006. Influence of the dam and sire on size at birth and subsequent growth, milk production and fertility in dairy heifers. Theriogenology 66:1173-1184.

Takeshima, S., Y. Matsumoto, J. Chen, T. Yoshida, H. Mukoyama, and Y. Aida. 2008. Evidence for cattle major histocompatibility complex (BoLA) class II DQA1 gene heterozygote advantage against clinical mastitis caused by Streptococci and Escherichia species. Tissue Antigens 72:525-531.

Thomas, T. 2004. The complex effects of leptin on bone metabolism through multiple pathways. Curr. Opin. Pharmacol. 4:295-300.

Thorn, S. R., M. J. Meyer, M. E. van Amburgh, and Y. R. Boisclair. 2007. Effect of estrogen on leptin and expression of leptin receptor transcripts in prepubertal dairy heifers. J. Dairy Sci. 90:3742-3750.

Truchet, S., M. Chebrout, C. Djediat, J. Wietzerbin, and P. Debey. 2004. Presence of permanently activated signal transducers and activators of transcription in nuclear interchromatin granules of unstimulated mouse oocytes and preimplantation embryos. Biol. Reprod. 71:1330-1339.

van der Lende, T., M. F. W. te Pas, R. F. Veerkamp, S. C. Liefers, and L. Gerald. 2005. Leptin gene polymorphisms and their phenotypic associations. Vitam. Horm. 71:373-404.

Wathes, D. C., N. Bourne, Z. Cheng, G. E. Mann, V. J. Taylor, and M. P. Coffey. 2007a. Multiple correlation analyses of metabolic and endocrine profiles with fertility in primiparous and multiparous cows. J. Dairy Sci. 90:1310-1325.

Wathes, D. C., Z. Cheng, N. Bourne, V. J. Taylor, M. P. Coffey, and S. Brotherstone. 2007b. Differences between primiparous and multiparous dairy cows in the inter-relationships between metabolic traits, milk yield and body condition score in the periparturient period. Domest. Anim. Endocrinol. 33:203-225.

Weedon, M. N., and T. M. Frayling. 2008. Reaching new heights: Insights into the genetics of human stature. Trends Genet. 24:595603.

Welham, S., B. R. Cullis, B. J. Gogel, A. R. Gilmour, and R. Thompson. 2004. Prediction in linear mixed models. Aust. N. Z. J. Stat. $46: 325-347$

Ye, Y., K. Kawamura, M. Sasaki, N. Kawamura, P. Groenen, M. D. Sollewijn Gelpke, J. Kumagai, J. Fukuda, and T. Tanaka. 2009. Leptin and ObRa/MEK signalling in mouse oocyte maturation and preimplantation embryo development. Reprod. Biomed. Online 19:181-190.

Zieba, D. A., M. Amstalden, and G. L. Williams. 2005. Regulatory roles of leptin in reproduction and metabolism: A comparative review. Domest. Anim. Endocrinol. 29:166-185. 